\title{
Stroke in Coronavirus Disease 2019: A Systematic Review
}

\author{
Rohit Bhatia, a,* Radhakrishna Pedapati, ${ }^{\text {a,* }}$ Snigdha Komakula, ${ }^{\text {a,* }}$ M.V. Padma Srivastava, ${ }^{\mathrm{a}}$ \\ Sreenivas Vishnubhatla, ${ }^{\mathrm{b}}$ Dheeraj Khurana ${ }^{\mathrm{c}}$ \\ aDepartment of Neurology, All India Institute of Medical Sciences, New Delhi, India \\ ${ }^{b}$ Department of Biostatistics, All India Institute of Medical Sciences, New Delhi, India \\ 'Department of Neurology, Postgraduate Institute of Medical Education and Research, Chandigarh, India
}

Background and Purpose Various neurological findings including stroke in patients with coronavirus disease 2019 (COVID-19) have been described, although no clarity exists regarding the nature and pattern of this association. This systematic review aims to report the characteristics of stroke in patients with COVID-19.

Methods Three authors independently searched Web of Science, Embase, Scopus, and PubMed starting from inception up to May 22, 2020. The data for individual patients was extracted where available from published reports including clinical and laboratory parameters and analysed for any significant associations between variables.

Results We identified 30 relevant articles involving 115 patients with acute or subacute stroke with COVID-19. The mean \pm standard deviation age was $62.5 \pm 14.5$ years. Stroke was ischemic in majority of the patients (101 [87.8\%]). Hypertension (42 [42\%]), dyslipidaemia (24 [26.1\%]), and diabetes (23 [23.2\%]) were the major vascular risk factors. Most of the patients (80 [85.1\%]) had COVID-19 symptoms at the time of stroke with a median interval of 10 days to stroke from the diagnosis of COVID-19. Three-fourths (86 [74.8\%]) of the patients were critically ill which frequently delayed the diagnosis of stroke. High levels of D-dimer, and ferritin were observed in these patients. Patients with COVID-19 and stroke had a high mortality (47.9\%). Factors associated with mortality were intensive care unit admission, having two or more vascular risk factors, particularly smoking and high levels of D-dimer, C-reactive protein, and lactate dehydrogenase.

Conclusions The association between stroke and COVID-19 is probably multifactorial including an amalgamation of traditional vascular risk factors, proinflammatory and a prothrombotic state. Prospectively collected data is required in the future to confirm this hypothesis.

Keywords Stroke; COVID-19; Severe acute respiratory syndrome coronavirus 2; Clinical trial; Systematic review; Virus diseases
Correspondence: Rohit Bhatia Department of Neurology, All India Institute of Medical Sciences, Sri Aurobindo Marg, Ansari Nagar, Ansari Nagar East, New Delhi 10029, India Tel: +91-11-26546625 Fax: +91-11-26588663 E-mail: rohitbhatia71@yahoo.com https://orcid.org/0000-0001-76623202

*These authors contributed equally to the manuscript as first author.

Received: June 10, 2020

Revised: August 3, 2020

Accepted: August 10, 2020

\section{Introduction}

The coronavirus disease 2019 (COVID-19) caused by severe acute respiratory syndrome coronavirus 2 (SARS-CoV-2) is a global health emergency. What started as a cluster of pneumonia cases in Wuhan, China, rapidly escalated to a worldwide pandemic, paralyzing human activities and causing enormous deaths. ${ }^{1}$ As on the day of submission of this manuscript, 7,039,918 people 
have developed the disease and 404,396 have died. ${ }^{2}$

Various papers over the recent times have commented upon the clinical characteristics, complications and outcome of patients infected with COVID-19.,4 Amongst the varied manifestations of COVID-19, neurological features have been highlighted by numerous authors. ${ }^{5-7}$ Stroke is one of the common comorbidities that has been described. Ischemic stroke (IS), intracerebral haemorrhage $(\mathrm{ICH})$, and cerebral venous thrombosis (CVT) have all been reported with variable frequencies. ${ }^{8-10}$ However, no clarity exists whether COVID-19 is causative or just co-exists or triggers the occurrence of stroke. It is imperative to glean from the published data, stroke characteristics like type, severity, underlying vascular risk factors, biochemical and prothrombotic abnormalities and outcome. Synthesizing this information will provide a clearer overview and may help understand the relation between stroke and COVID-19. This systematic review aims to analyse the information reported among published studies of stroke in COVID-19.

\section{Methods}

The systematic review has been carried out in accordance with the recommendations of the Preferred Reporting Items for Systematic Reviews and Meta-Analyses (PRISMA) statement. ${ }^{11}$ However, the protocol was not pre-registered in view of time constraints.

\section{Literature search}

Three authors independently searched Web of Science, EMBASE, Scopus, and PubMed to identify articles evaluating both COVID-19 and Stroke starting from inception up to May 22, 2020. The three authors participated in each phase of the review independently (screening, eligibility, and inclusion). Individual databases were searched with the terms 'COVID-19 AND stroke', 'COVID-19 AND cerebrovascular disease,' 'COVID-19 AND ischemic stroke,' 'COVID-19 AND ICH', 'COVID-19 AND intracerebral haemorrhage,' 'COVID-19 AND neurology', 'SARS-CoV-2 AND stroke, 'SARS-CoV-2 AND cerebrovascular disease,' 'SARS-CoV-2 AND ischemic stroke,' 'SARS-CoV-2 AND ICH', 'SARS-CoV-2 AND intracerebral haemorrhage,' 'SARS-CoV-2 AND neurology,' 'Thrombolysis AND COVID-19', 'Thrombectomy AND COVID-19', 'Thrombolysis AND SARS-CoV-2', 'Thrombectomy AND SARSCoV-2,' 'Stroke imaging AND COVID-19', without any filters. No language restrictions were applied. Database searches were combined, and duplicates were removed. Titles and abstracts were then reviewed for relevance and full texts of the relevant articles were evaluated for eligibility. To ensure literature saturation, the authors scanned the reference lists of the included studies or relevant reviews identified through the search. Studies not meeting inclusion criteria or having one or more exclusion criteria were filtered. Any disagreement regarding search strategy, inclusion or exclusion criteria was resolved through discussions. None of the authors were blind to the journal titles, study authors or institutions. Data from each article was extracted into an excel sheet with predefined variables.

\section{Inclusion criteria}

All published trials, observational studies, case series and case reports mentioning stroke in at least one patient either as a complication of COVID-19 or occurrence in a close temporal relationship to COVID-19 diagnosis (acute to subacute stroke).

\section{Exclusion criteria}

All review articles, consensus statements, letter to the editors which did not have clinical information related to patients with stroke and COVID-19 were excluded.

\section{Data extraction}

The following data was extracted from the included studies wherever available: study author(s), study design, individual patient data including age, sex, severity of COVID-19, presence or absence of COVID-19 symptoms at the onset or diagnosis of stroke, type of stroke, days from the diagnosis of COVID-19 to onset or diagnosis of stroke, imaging, comorbidities, laboratory values, treatment, and outcome. Trial of ORG 10172 in Acute Stroke Treatment (TOAST) ${ }^{12}$ classification for stroke subtype was extracted if specifically mentioned and based on radiological and other information available. All patients admitted in the intensive care unit (ICU) were considered "critically ill" in the present review. The clinical outcomes variably reported in articles were grouped into three categories; 'survivors', 'still hospitalized at the time of publication, or 'non-survivors' for whom such data was available. Where no information on outcome was available at all, the patients were grouped in the "no information" category and their outcomes could not be analysed.

\section{Quality assessment}

We have rated the level of evidence for individual studies according to Oxford Centre for Evidence-based Medicine's Levels of Evidence and Grades of Recommendation (Supplementary Table 1). ${ }^{13}$ Risk of bias was not assessed systematically.

\section{Characteristics and outcome assessment}

The data was analysed to observe demographics, stroke types, severity of clinical status, vascular risk factors, TOAST classifi- 
cation of IS, biochemical data, and mortality. We compared the clinical, imaging, and/or laboratory variables between (1) patients who had symptoms of COVID-19 at the time of stroke and those who did not; (2) patients who were critically ill and those who were not; and (3) survivors and non-survivors. Predictors of mortality were also analysed.

\section{Statistical analysis}

Categorical variables are expressed as frequencies. Continuous variables which had a normal or near normal distribution are expressed as mean \pm standard deviation (SD) and those which did not have normal distribution are expressed as medians with interquartile ranges (IQRs). Comparisons between categorical variables was done by chi-square test and continuous variables was done by independent t-test or Mann-Whitney U-test wherever applicable. Logistic regression was applied to determine independent predictors of survival and odds ratio calculated wherever applicable. A two tailed $P$-value of $\leq 0.05$ was taken as significant. All the analyses were done using Stata version 15.1 (StataCorp., College Station, TX, USA).

\section{Results}

Of 2,801 articles yielded from initial search, 30 were included for our final analysis (Figure 1). The various keyword sets used in the literature search are mentioned in the methodology section and their results are outlined in Supplementary Table 2. Among 30 records included in the final analysis, 16 were case reports, eight

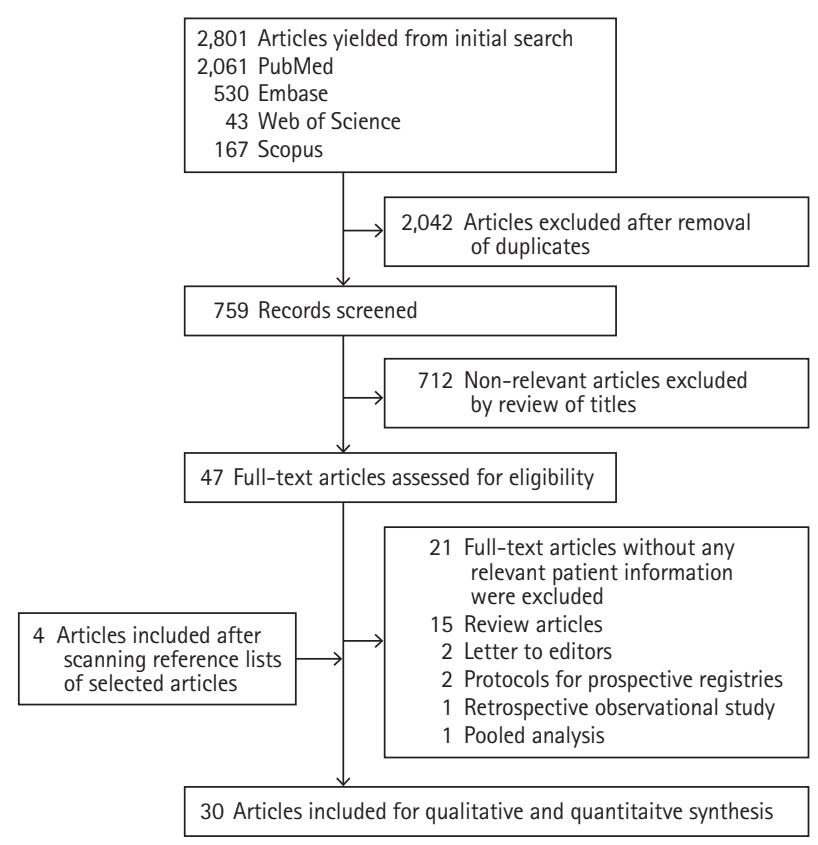

Figure 1. Flow chart of study selection. were case series, five were retrospective observational studies, and one was a prospective observational study. The characteristics of all the 30 records are outlined in Supplementary Table 3. The risk of bias was not assessed systematically but was likely to be high in all studies since most of them were case reports, case series, and retrospective observational studies.

A total of 115 patients with acute or subacute stroke infected with SARS-CoV-2 from the 30 studies included were analysed in this systematic review. Majority of the variables had missing data and those patients with the missing data for a certain variable were excluded from analysis of the given variable. The characteristics of the patients are presented in Table 1.

The mean \pm SD age of the patients was $62.5 \pm 14.5$ years. Majority of the patients were males (42 [62\%]). IS (101 [87.8\%]) was the most common type of stroke followed by ICH (6 [5.2\%]) and CVT (3 [2.6\%]). Two patients had both ICH and subarachnoid haemorrhage (SAH) (1.7\%), one patient (0.9\%) each had SAH and transient ischemic attack (TIA) and one patient $(0.9 \%)$ had both SAH and IS. The median number of days to the onset (detection in case of unclear onset) of stroke was 10 days with half of all strokes occurring within the first 10 days of the COVID-19 diagnosis. Approximately one-third of all strokes occurred within an additional 10 days from the diagnosis of COVID-19. The median National Institutes of Health Stroke Scale (NIHSS) score was 11.5, but this data was available only for 16 patients. Among 89 patients where data was available, presentation of clinical stroke syndrome could be identified in 70 (78.7\%) patients, the rest being diagnosed on cranial imaging done for any change in neurological status during admission.

The most common risk factor identified was hypertension (HTN, 42 [42\%]), followed by dyslipidaemia (24 [26.1\%]), diabetes mellitus (23 [23.2\%]), atrial fibrillation (AF, 11 [11.2\%]), coronary artery disease (10 [10.2\%]), smoking (9 [14.3\%]), previous stroke (7 [7.1\%]), heart failure (4 [4.1\%]), alcoholism (3 [5.2\%]), and pacemaker (1 [1\%]). Five patients had malignancies including lung (two patients), prostrate (one patient), stomach (one patient), and nasopharyngeal cancer (one patient). One patient each had chronic kidney disease and chronic obstructive lung disease. The most common subtype of IS was large artery atherosclerosis (LAD) (25 [35.2\%]) followed by cryptogenic (23 [32.4\%]), cardioembolic (CE, 10 [14.1\%]), other determined causes $(7[9.9 \%])$, and small vessel disease (6 [8.4\%]) respectively. As per the available data, five patients had positive anticardiolipin antibodies (Table 1) with immunoglobulin $\mathrm{M}(\mathrm{IgM})$ in two and IgA in three patients. Among these patients, anti- $\beta 2-$ glycoprotein I IgA and $\lg G$ were present in three patients as well. No absolute titres were available from the studies. Five 
Table 1. Baseline characteristics of the patients*

\begin{tabular}{|c|c|}
\hline Characteristic & All patients $(n=115)$ \\
\hline Age $(n=100)(y r)$ & $62.5 \pm 14.5$ \\
\hline \multicolumn{2}{|l|}{$\operatorname{Sex}(n=68)$} \\
\hline Female & $26(38.2)$ \\
\hline Male & $42(61.8)$ \\
\hline Symptomatic for COVID-19 at the time of stroke $(n=94)$ & $80(85.1)$ \\
\hline \multicolumn{2}{|l|}{ Type of stroke $(n=115)$} \\
\hline Ischaemic stroke & $101(87.8)$ \\
\hline Intracerebral haemorrhage & $6(5.2)$ \\
\hline Intracerebral haemorrhage with subarachnoid haemorrhage & $2(1.7)$ \\
\hline Cerebral venous thrombosis & $3(2.6)$ \\
\hline Ischaemic stroke with subarachnoid haemorrhage & $1(0.9)$ \\
\hline Subarachnoid haemorrhage & $1(0.9)$ \\
\hline Transient ischaemic attack & $1(0.9)$ \\
\hline NIHSS $(n=16)$ & $11.5(3.3-18.3)$ \\
\hline \multicolumn{2}{|l|}{ TOAST category $(n=71)$} \\
\hline Large artery disease & $25(35.2)$ \\
\hline Small vessel disease & $6(8.4)$ \\
\hline Cardioembolic & $10(14.1)$ \\
\hline Other & $7(9.9)$ \\
\hline Cryptogenic & $23(32.4)$ \\
\hline Critical illness $(n=115)$ & $86(74.8)$ \\
\hline \multicolumn{2}{|l|}{ Imaging modality for stroke $(n=95)$} \\
\hline CT & $84(88.4)$ \\
\hline Magnetic resonance imaging & $11(11.6)$ \\
\hline \multicolumn{2}{|l|}{ Vascular imaging $(n=56)$} \\
\hline CT angiography & $52(92.9)$ \\
\hline Magnetic resonance angiography & $4(7.1)$ \\
\hline Abnormal chest X-ray $(n=13)$ & $11(84.6)$ \\
\hline Abnormal CT chest $(n=46)$ & $46(100)$ \\
\hline Abnormal CT pulmonary angiography $(n=8)$ & $5(62.5)$ \\
\hline Days to stroke from diagnosis of COVID-19 $(n=73)$ & $10(5-15)$ \\
\hline Stroke suspected clinically ( $n=89$ ) & $70(78.7)$ \\
\hline \multicolumn{2}{|l|}{ Risk factors } \\
\hline Hypertension $(n=100)$ & $42(42.0)$ \\
\hline Diabetes $(n=99)$ & $23(23.2)$ \\
\hline Old stroke $(n=99)$ & $7(7.1)$ \\
\hline Smoking $(n=63)$ & $9(14.3)$ \\
\hline Atrial fibrillation $(n=98)$ & $11(11.2)$ \\
\hline Heart failure $(n=98)$ & $4(4.1)$ \\
\hline Pacemaker $(n=98)$ & $1(1.0)$ \\
\hline Dyslipidemia $(n=92)$ & $24(26.1)$ \\
\hline Coronary artery disease $(n=98)$ & $10(10.2)$ \\
\hline Alcoholism $(n=58)$ & $3(5.2)$ \\
\hline \multicolumn{2}{|l|}{ Comorbidities } \\
\hline Chronic kidney disease $(n=15)$ & $1(6.7)$ \\
\hline
\end{tabular}


Table 1. Continued

\begin{tabular}{|c|c|}
\hline Characteristic & All patients $(n=115)$ \\
\hline Chronic obstructive pulmonary disease $(n=16)$ & $1(6.3)$ \\
\hline Cancer $(n=19)$ & $5(26.3)$ \\
\hline \multicolumn{2}{|l|}{ Treatment $(n=96)$} \\
\hline Tissue plasminogen activator & $13(13.5)$ \\
\hline Endovascular thrombectomy & $14(14.6)$ \\
\hline Anticoagulant & $54(56.3)$ \\
\hline Antiplatelet & $33(34.4)$ \\
\hline Outcome mortality $(\mathrm{n}=90)$ & $35(47.9)$ \\
\hline C-reactive protein $(\mathrm{n}=63)(\mathrm{mg} / \mathrm{L})$ & $101.1(31.6-179.9)$ \\
\hline D-dimer $(n=69)(\mu \mathrm{g} / \mathrm{L})$ & $3,442(1,159-10,000)$ \\
\hline Ferritin $(n=17)(\mu \mathrm{g} / \mathrm{L})$ & $655(134-1,708)$ \\
\hline Leucocyte count $(n=29)\left(\times 10^{9} / L\right)$ & $8.7(6.7-11.7)$ \\
\hline Lymphocyte $(n=25)\left(\times 10^{9} / L\right)$ & $0.9 \pm 0.5$ \\
\hline Platelet $(n=27)\left(\times 10^{9} / L\right)$ & $183(141-305)$ \\
\hline Creatinine $(n=20)(\mu \mathrm{mol} / \mathrm{L})$ & $92.84(71.3-120.3)$ \\
\hline Aspartate transaminase $(n=15)(U / L)$ & $35(23-97)$ \\
\hline Alanine transaminase $(n=18)(U / L)$ & $31(17.3-51.3)$ \\
\hline Procalcitonin $(n=8)(\mu g / L)$ & $0.45(0.13-2.77)$ \\
\hline Troponin $(\mathrm{n}=24)(\mathrm{pg} / \mathrm{mL})$ & $215(34.5-876.8)$ \\
\hline Lactate dehydrogenase $(n=20)(U / L)$ & $546 \pm 254$ \\
\hline Activated partial thromboplastin time $(n=19)(\mathrm{sec})$ & $35 \pm 13$ \\
\hline International normalized ratio $(n=11)$ & $1.14(1.05-1.53)$ \\
\hline Prothrombin time $(n=10)$ & $14.1(13.2-15.7)$ \\
\hline Fibrinogen $(n=16)(g / L)$ & $5.5 \pm 1.8$ \\
\hline APLA positivity $(n=14)$ & $5(35.7)$ \\
\hline Lupus anticoagulant $(n=11)$ & $5(45.5)$ \\
\hline
\end{tabular}

Values are presented as mean \pm standard deviation, number (\%), or median (interquartile range).

COVID-19, coronavirus disease 2019; NIHSS, National Institutes of Health Stroke Scale; TOAST, Trial of ORG 10172 in Acute Stroke Treatment; CT, computed tomography; APLA, antiphospholipid antibody.

*Data is not uniformly available for each patient leading to separate ' $n$ ' number for each characteristic.

patients had lupus anticoagulant (LA) positive (Table 1).

Computed tomography (CT) scan of brain and CT angiography were the predominant structural and vascular imaging modalities employed for stroke, respectively. Brain imaging patterns of ischemia were available for 39 patients (33.9\%). Most commonly observed pattern was uni-hemispheric, anterior circulation infarct confined to a single vascular territory (19 [48.7\% of 39]) with majority (14 [73.7\%]) of them having large artery disease. Eleven patients (28.2\% of 39 ) had bi-hemispheric infarcts in multiple vascular territories with majority (7 [63.6\% of 11]) of them having either positive antiphospholipid antibody (APLA) or LA. Five patients (12.8\% of 39$)$ had posterior circulation stroke in a single vascular territory, three (7.6\% of 39) had lacunar strokes and one (2.5\% of 39) patient had uni-hemispheric infarcts in more than one vascular territory. Of 13 patients with available information on chest X-ray, 11 (84.6\%) had abnormal findings suggestive of COVID-19. CT chest was found abnormal for all patients $(n=46)$ who underwent. Eight patients underwent CT pulmonary angiography and five $(62.5 \%)$ of them were diagnosed with pulmonary embolism.

Eighty (85.1\%) patients were symptomatic for COVID 19 at the time of presentation with stroke. The differences between patients with or without symptoms for COVID-19 at the time of stroke are outlined in Table 2. The mean age of those who were symptomatic for COVID-19 at the time of stroke was significantly more ( $64 \pm 17$ years) than that of those who were asymptomatic ( $55 \pm 17$ years; $P=0.05)$. The $C$-reactive protein (CRP) was significantly higher in those who have symptoms specific to COVID-19 at the time of stroke (mean \pm SD of $129.9 \pm 14.3 \mathrm{mg} / \mathrm{L})$ than those who did not $(55.3 \pm 67.1 \mathrm{mg} / \mathrm{L}$; 
Table 2. Comparison of characteristics between patients with and without symptoms of COVID-19 at the time of stroke*

\begin{tabular}{|c|c|c|c|}
\hline Characteristic & $\begin{array}{l}\text { Symptomatic } \\
\quad(n=80)\end{array}$ & $\begin{array}{l}\text { Asymptomatic } \\
\quad(n=14)\end{array}$ & $P^{+}$ \\
\hline Age $(n=88)(y r)$ & $64 \pm 17$ & $55 \pm 17$ & 0.05 \\
\hline $\begin{array}{l}\text { C-reactive protein }(\mathrm{n}=60) \\
(\mathrm{mg} / \mathrm{L})\end{array}$ & $130 \pm 103$ & $55 \pm 67$ & 0.02 \\
\hline$D-\operatorname{dimer}(n=58)(\mu \mathrm{g} / \mathrm{L})$ & $7,417 \pm 12,010$ & $6,932 \pm 8,880$ & 0.76 \\
\hline Ferritin $(n=17)(\mu \mathrm{g} / \mathrm{L})$ & $1,290 \pm 1,613$ & $956 \pm 737$ & 0.71 \\
\hline $\begin{array}{l}\text { Leucocyte count }(\mathrm{n}=28) \\
\left(\times 10^{9} / \mathrm{L}\right)\end{array}$ & $9.3 \pm 4.5$ & $10.5 \pm 4.6$ & 0.36 \\
\hline $\begin{array}{l}\text { Lymphocyte count }(\mathrm{n}=25) \\
\left(\times 10^{9} / \mathrm{L}\right)\end{array}$ & $0.9 \pm 0.5$ & $1.1 \pm 0.5$ & 0.52 \\
\hline Platelet $(n=27)\left(\times 10^{9} / L\right)$ & $213.3 \pm 113.7$ & $261.7 \pm 116.8$ & 0.64 \\
\hline Creatinine $(n=20)(\mu \mathrm{mol} / \mathrm{L})$ & $117 \pm 99$ & $136 \pm 27$ & 0.08 \\
\hline $\begin{array}{l}\text { Aspartate transaminase } \\
(\mathrm{n}=15)(\mathrm{U} / \mathrm{L})\end{array}$ & $53 \pm 42$ & $52 \pm 45$ & 0.77 \\
\hline $\begin{array}{l}\text { Alanine transaminase }(n=18) \\
(\mathrm{U} / \mathrm{L})\end{array}$ & $43 \pm 33$ & $19 \pm 5$ & 0.08 \\
\hline Procalcitonin $(n=8)(\mu \mathrm{g} / \mathrm{L})$ & $3.2 \pm 5.5$ & $0.3 \pm 0.3$ & 0.32 \\
\hline Troponin $(\mathrm{n}=23)(\mathrm{pg} / \mathrm{mL})$ & $1,405 \pm 4,027$ & $1,623 \pm 1,441$ & 0.68 \\
\hline $\begin{array}{l}\text { Lactate dehydrogenase } \\
\qquad(n=20)(U / L)\end{array}$ & $576 \pm 260$ & $429 \pm 214$ & 0.31 \\
\hline aPTT $(n=19)(\mathrm{sec})$ & $36 \pm 14$ & $31 \pm 9.9$ & 0.60 \\
\hline $\begin{array}{l}\text { International normalized } \\
\quad \text { ratio }(n=11)\end{array}$ & $1.5 \pm 0.78$ & $0.99^{\ddagger}$ & 0.11 \\
\hline Prothrombin time $(n=10)$ & $14.6 \pm 1.9$ & $13.9 \pm 0.7$ & 0.9 \\
\hline Fibrinogen $(n=16)(g / L)$ & $5.5 \pm 1.9$ & $5.2 \pm 1.9$ & 0.80 \\
\hline APLA positivity $(n=14)$ & $5(35.7)$ & $0(0)$ & 0.44 \\
\hline Lupus anticoagulant $(\mathrm{n}=11)$ & $4(36.4)$ & $1(9.1)$ & 0.25 \\
\hline
\end{tabular}

Values are presented as mean \pm standard deviation or number (\%). COVID-19, coronavirus disease 2019; aPT, activated partial thromboplastin time; APLA, antiphospholipid antibody.

*Data is not uniformly available for each patient leading to separate ' $n$ ' number for each characteristic; ${ }^{+}$Chi-square test was used for categorical variables and Mann-Whitney test was used for continuous variables to calculate $P$-value unless otherwise specified; ${ }^{\ddagger}$ Only single observation was available.

$P=0.02$ ). Rest of the laboratory parameters did not differ between symptomatic and asymptomatic patients.

Three-fourths (86 [74.8\%]) of the patients were in critical condition requiring ICU admission. The characteristics of these patients when compared with those who were not critically ill are mentioned in Table 3. These patients had a longer time to the onset (detection in case of unclear onset) of stroke (13.2 \pm 8.7 days) when compared to those who were not critically ill (4.8 \pm 4.3 days; $P=0.0002$ ). The stroke was identified on imaging obtained for reasons other than clinical suspicion of acute stroke in $19(21.3 \%)$ patients and all of them were critically ill $(P=0.01)$. The CRP levels were not significantly different in critically ill and non-critically ill patients though there was a trend of CRP being
Table 3. Comparison of characteristics between patients with and without being critically ill*

\begin{tabular}{|c|c|c|c|}
\hline Characteristic & $\begin{array}{l}\text { Critically ill } \\
(n=86)\end{array}$ & $\begin{array}{l}\text { Non-critically ill } \\
(n=29)\end{array}$ & $P^{+}$ \\
\hline $\begin{array}{l}\text { Time to stroke in days }{ }^{\mp} \\
(\mathrm{n}=70)\end{array}$ & $13 \pm 9$ & $5 \pm 4$ & $0.0002^{\S}$ \\
\hline Clinical stroke" $(n=89)$ & & & $0.01^{\S}$ \\
\hline Yes & $50(56.2)$ & $20(22.5)$ & \\
\hline No & 19 (21.3) & $0(0)$ & \\
\hline $\begin{array}{l}\text { C-reactive protein ( } \mathrm{n}=63) \\
(\mathrm{mg} / \mathrm{L})\end{array}$ & $130 \pm 102$ & $88 \pm 96$ & 0.08 \\
\hline D-dimer $(n=69)(\mu \mathrm{g} / \mathrm{L})$ & $7,625 \pm 11,936$ & $7,712 \pm 14,007$ & 0.06 \\
\hline Ferritin $(n=17)(\mu g / L)$ & $2,691 \pm 1,661$ & $434 \pm 400$ & $0.002^{\S}$ \\
\hline $\begin{array}{l}\text { Leucocyte count }(\mathrm{n}=29) \\
\left(\times 10^{9} / \mathrm{L}\right)\end{array}$ & $11.1 \pm 5.9$ & $8.1 \pm 2.2$ & 0.30 \\
\hline $\begin{array}{l}\text { Lymphocyte count }(n=25) \\
\left(\times 10^{9} / L\right)\end{array}$ & $0.8 \pm 0.5$ & $1.1 \pm 0.5$ & 0.10 \\
\hline Platelet $(n=27)\left(\times 10^{9} / L\right)$ & $195.3 \pm 106.1$ & $292.3 \pm 108.3$ & $0.04^{\S}$ \\
\hline Creatinine $(n=20)(\mu \mathrm{mol} / \mathrm{L})$ & $127 \pm 108$ & $104 \pm 32$ & 0.62 \\
\hline $\begin{array}{l}\text { Aspartate transaminase } \\
(n=15)(U / L)\end{array}$ & $56 \pm 42$ & $27 \pm 12$ & 0.27 \\
\hline $\begin{array}{l}\text { Alanine transaminase } \\
\qquad(\mathrm{n}=18)(\mathrm{U} / \mathrm{L})\end{array}$ & $39 \pm 36$ & $39 \pm 22$ & 0.57 \\
\hline Procalcitonin $(n=8)(\mu \mathrm{g} / \mathrm{L})$ & $2.8 \pm 5.1$ & $0.08^{\uparrow}$ & 0.13 \\
\hline Troponin $(\mathrm{n}=24)(\mathrm{pg} / \mathrm{mL})$ & $1,786 \pm 4,143$ & $67 \pm 77$ & $0.02^{\S}$ \\
\hline $\begin{array}{l}\text { Lactate dehydrogenase } \\
\qquad(n=20)(U / L)\end{array}$ & $628 \pm 255$ & $356 \pm 113$ & $0.02^{5}$ \\
\hline aPTT (n=19) (sec) & $37 \pm 16$ & $32 \pm 7$ & 0.42 \\
\hline $\begin{array}{l}\text { International normalized } \\
\quad \text { ratio }(n=11)\end{array}$ & $1.62 \pm 0.9$ & $1.1 \pm 0.6$ & $0.02^{5}$ \\
\hline Prothrombin time $(n=10)$ & $14.6 \pm 1.97$ & $13.96 \pm 1.06$ & 0.73 \\
\hline Fibrinogen $(n=16)(g / L)$ & $6.3 \pm 1.9$ & $4.5 \pm 1.1$ & $0.04^{\S}$ \\
\hline
\end{tabular}

Values are presented as mean \pm standard deviation or number (\%). aPTT, activated partial thromboplastin time; APLA, antiphospholipid antibody.

*Data is not uniformly available for each patient leading to separate ' $n$ ' number for each characteristic; ${ }^{+}$Chi-square test was used for categorical variables and Mann-Whitney test was used for continuous variables to calculate $P$-value unless otherwise specified; "Time from diagnosis of coronavirus disease 2019 to the onset (detection if onset unclear) of stroke; ${ }^{\text {SD Dif- }}$ ference between groups was statistically significant; "Stroke suspected

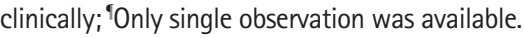

higher in the former group. The values of ferritin were significantly higher in critically ill patients $(2,691 \pm 1,661)$ than those who were not $(434 \pm 400 \mu \mathrm{g} / \mathrm{L} ; P=0.002)$. Similarly, the platelet counts, troponin level, lactate dehydrogenase $(L D H)$, international normalised ratio, and fibrinogen levels, all differed significantly between these two groups as shown in Table 3.

Treatment details were available in 96 (83.4\%) patients. Twenty patients received reperfusion therapy. The mean age of these patients was $59.1 \pm 14.21$ years. The median NIHSS was 13 (IQR, 2 to 
Table 4. Differences between survivors and non-survivors*

\begin{tabular}{|c|c|c|c|c|}
\hline Characteristic & Survivors $(n=38)$ & Non-survivors $(n=35)$ & $P^{+}$ & OR $(95 \% \mathrm{Cl})^{+}$ \\
\hline Age $(n=73)(y r)$ & $60.5 \pm 16.6$ & $66.5 \pm 14.3$ & 0.1 & $1(0.9-1.1)$ \\
\hline $\operatorname{Sex}(n=50)$ & & & 0.3 & $0.5(0.2-1.7)$ \\
\hline Female & $15(30)$ & $7(14)$ & & \\
\hline Male & $15(30)$ & $13(26)$ & & \\
\hline Symptomatic for COVID-19 at the time of stroke $(n=64)$ & $27(42.2)$ & $27(42.2)$ & 0.56 & $1.5(0.4-6)$ \\
\hline Type of stroke $(n=73)$ & & & 0.14 & $1.1(0.3-4.1)^{\S}$ \\
\hline Ischaemic stroke & $32(43.8)$ & $30(41.1)$ & & \\
\hline Intracerebral haemorrhage & $0(0)$ & $4(5.5)$ & & \\
\hline Intracerebral haemorrhage with subarachnoid haemorrhage & $2(2.7)$ & $1(1.4)$ & & \\
\hline Cerebral venous thrombosis & $2(2.7)$ & $0(0)$ & & \\
\hline Subarachnoid haemorrhage & $1(1.4)$ & $0(0)$ & & \\
\hline Transient ischaemic attack & $1(1.4)$ & $0(0)$ & & \\
\hline NIHSS $(n=13)$ & $11.5(4.5-16.8)$ & $2(2-36)$ & 0.74 & $1(0.9-1.2)$ \\
\hline TOAST $(n=52)$ & & & 0.2 & \\
\hline Large artery disease & $12(23.1)$ & $7(13.5)$ & & $0.5(0.1-2.3)$ \\
\hline Small vessel disease & $5(9.6)$ & $1(1.9)$ & & $0.16(0.01-1.9)$ \\
\hline Cardioembolic & $4(7.7)$ & $5(9.6)$ & & $1.3(0.3-4.7)$ \\
\hline Other & $0(0)$ & $1(1.9)$ & & NA \\
\hline Cryptogenic & $6(11.5)$ & $11(21.2)$ & & $1.5(0.3-7.6)$ \\
\hline \multicolumn{5}{|l|}{ Critical illness $(n=73)$} \\
\hline No & $21(28.8)$ & $2(2.7)$ & & $0.1(0.02-0.4)$ \\
\hline Yes & $17(23.3)$ & $33(45.2)$ & $<0.001^{\|}$ & $20.4(4.3-97)$ \\
\hline Chest X-ray $(n=8)$ & & & 0.3 & NA \\
\hline Normal & $1(12.5)$ & $0(0)$ & & \\
\hline Abnormal & $3(37.5)$ & $4(50)$ & & \\
\hline Abnormal CT chest $(n=37)$ & $20(54.1)$ & $17(45.9)$ & NA & NA \\
\hline Abnormal CT pulmonary angiography $(n=3)$ & $1(33.3)$ & $1(33.3)$ & 0.4 & NA \\
\hline \multicolumn{5}{|l|}{ Risk factors } \\
\hline Hypertension $(n=72)$ & $14(19.4)$ & $16(22.2)$ & 0.4 & $1.5(0.6-3.9)$ \\
\hline Diabetes $(n=72)$ & $7(9.7)$ & $11(15.3)$ & 0.2 & $2.1(0.7-6.3)$ \\
\hline Old stroke $(n=72)$ & $1(1.4)$ & $2(2.8)$ & 0.5 & $2.3(0.2-27)$ \\
\hline Smoking $(n=47)$ & $2(4.3)$ & $6(12.8)$ & $0.03^{\prime \prime}$ & $6(1.1-33.9)$ \\
\hline Atrial fibrillation $(n=72)$ & $4(5.6)$ & $4(5.6)$ & 0.9 & $1.1(0.3-4.9)$ \\
\hline Heart failure $(n=72)$ & $0(0)$ & $3(4.2)$ & 0.06 & NA \\
\hline Pacemaker $(n=72)$ & $0(0)$ & $1(1.4)$ & 0.3 & NA \\
\hline Dyslipidemia $(n=65)$ & $6(9.2)$ & $11(16.9)$ & 0.052 & $3(0.96-9.7)$ \\
\hline Coronary artery disease $(n=72)$ & $1(1.4)$ & $5(6.9)$ & 0.06 & $6.4(0.7-58)$ \\
\hline Alcoholism $(n=42)$ & $1(2.4)$ & $1(2.4)$ & 0.66 & $1.9(0.1-32)$ \\
\hline \multicolumn{5}{|l|}{ No. of risk factors $(n=72)$} \\
\hline 0 & $16(22.2)$ & $3(4.2)$ & $0.004^{\prime \prime}$ & $0.2(0.05-0.6)$ \\
\hline 1 & $7(9.7)$ & $6(8.3)$ & & $4.6(0.9-24)$ \\
\hline$\geq 2$ & $15(20.8)$ & $25(34.7)$ & & $8.9(2.2-35.7)$ \\
\hline \multicolumn{5}{|l|}{ Comorbidities } \\
\hline Chronic kidney disease $(n=8)$ & $1(12.5)$ & $0(0)$ & 0.7 & NA \\
\hline Cancer $(n=10)$ & $1(10)$ & $1(10)$ & 0.5 & $3(0.1-73.6)$ \\
\hline
\end{tabular}


Table 4. Continued

\begin{tabular}{|c|c|c|c|c|}
\hline Characteristic & Survivors $(n=38)$ & Non-survivors $(n=35)$ & $P^{+}$ & OR $(95 \% \mathrm{Cl})^{+}$ \\
\hline C-reactive protein $(\mathrm{n}=44)(\mathrm{mg} / \mathrm{L})$ & $81 \pm 95$ & $125 \pm 83$ & $0.02^{\prime \prime}$ & $2.6(0.8-8.9)^{4}$ \\
\hline D-dimer $(n=44)(\mu \mathrm{g} / \mathrm{L})$ & $3,180 \pm 3,658$ & $9,314 \pm 13,032$ & $0.007^{\|}$ & $3.7(1.1-13)^{* *}$ \\
\hline Ferritin $(n=9)(\mu g / L)$ & $241 \pm 228$ & $1,853^{++}$ & 0.12 & NA \\
\hline Leucocyte count $(n=17)\left(\times 10^{9} / L\right)$ & $8.3 \pm 3$ & $14.1 \pm 7.7$ & 0.14 & $5.3(0.6-46)$ \\
\hline Lymphocyte $(n=15)\left(\times 10^{9} / L\right)$ & $1 \pm 0.5$ & $0.9 \pm 0.7$ & 0.5 & $0.8(0.1-6.3)$ \\
\hline Platelet $(n=14)\left(\times 10^{9} / L\right)$ & $245 \pm 93$ & $192 \pm 98$ & 0.1 & NA \\
\hline Creatinine $(n=10)(\mu \mathrm{mol} / \mathrm{L})$ & $113 \pm 45$ & $177 \pm 137$ & 0.7 & $1.5(0.1-25.4)$ \\
\hline Aspartate transaminase $(n=10)(U / L)$ & $50 \pm 37$ & $77 \pm 48$ & 0.5 & $2(0.1-27)$ \\
\hline Alanine transaminase $(n=8)(\mathrm{U} / \mathrm{L})$ & $31 \pm 18$ & $40 \pm 24$ & 0.65 & NA \\
\hline Procalcitonin $(n=4)(\mu g / L)$ & $0.08^{++}$ & $5.97 \pm 7.1$ & 0.17 & NA \\
\hline Troponin $(\mathrm{n}=11)(\mathrm{pg} / \mathrm{mL})$ & $310 \pm 348$ & $3,044 \pm 6,264$ & 0.36 & $1.2(0.7-19.6)$ \\
\hline Lactate dehydrogenase $(n=11)(U / L)$ & $302 \pm 99$ & $811 \pm 201$ & $0.008^{\prime \prime}$ & $N A^{\neq+}$ \\
\hline aPTT (n=8) (sec) & $26 \pm 14$ & $44 \pm 8.5$ & 0.17 & $8(0.3-206)$ \\
\hline International normalized ratio $(n=6)$ & $1.2 \pm 0$ & $1.95 \pm 1.1$ & 0.3 & NA \\
\hline Prothrombin time $(n=4)$ & $13.9 \pm 1.1$ & $13.8^{++}$ & 0.65 & NA \\
\hline Fibrinogen $(n=7)(g / L)$ & $4.9 \pm 1.9$ & $7^{++}$ & 0.32 & NA \\
\hline APLA positivity $(n=4)$ & $0(0)$ & $0(0)$ & NA & NA \\
\hline Lupus anticoagulant $(\mathrm{n}=2)$ & $0(0)$ & $1(50)$ & NA & NA \\
\hline
\end{tabular}

Values are presented as mean \pm standard deviation, number (\%), or median (interquartile range).

OR, odds ratio; $\mathrm{Cl}$, confidence interval; COVID-19, coronavirus disease 2019; NIHSS, National Institutes of Health Stroke Scale; TOAST, Trial of ORG 10172 in Acute Stroke Treatment; NA, not applicable; CT, computed tomography; aPTT, activated partial thromboplastin time; APLA, antiphospholipid antibody.

${ }^{*}$ Data is not uniformly available for each patient leading to separate ' $n$ ' number for each characteristic; ${ }^{\dagger}$ Chi-square test was used for categorical variables and Mann-Whitney test was used for continuous variables to calculate $P$-value unless otherwise specified; ${ }^{\ddagger} 0$ Rs were calculated by logistic regression. The cut-off values used for calculating ORs were upper or lower limits of normal values (whichever differentiates normal from abnormal values) unless otherwise specified; ${ }^{\S} \mathrm{OR}$ was calculated for ischaemic stroke when compared with non-ischaemic stroke; "The difference between the groups was statistically significant; ${ }^{\circledR} \mathrm{A}$ C-reactive protein (CRP) cut-off value of $100 \mathrm{mg} / \mathrm{L}$ was used arbitrarily to calculate the OR. The difference between the groups for CRP was significant by Mann-Whitney test even though the $\mathrm{Cl}$ for $\mathrm{OR}$ included $1 ;{ }^{*}{ }^{*} \mathrm{D}$-dimer cut-off of $4,000 \mu \mathrm{g} / \mathrm{L}$ was used arbitrarily to calculate $0 \mathrm{R}$; ${ }^{++}$Only single observation was available; ${ }^{*+}$ One of the cells in the contingency table used to calculate $\mathrm{OR}$ at a cut-off of $280 \mathrm{U} / \mathrm{L}$ of lactate dehydrogenase had null value precluding the calculation of the same.

23) at presentation and was available in only 10 patients. Intravenous or intraarterial recombinant tissue plasminogen activator (rTPA) was given to 13 patients (13.5\%; six without and seven combined with endovascular thrombectomy [EVT]), was not indicated in $24(25 \%)$ and no information was available in 59 (61.4\%). EVT was performed in 14 (14.6\%; alone in seven and in combination with rTPA in seven patients), was not indicated in 27 (28.1\%) and no information was available in 55 (57.2\%) patients. Door to CT, door to needle and door to puncture times were not available in most of the records even in strokes which occurred during the hospital stay and hence could not be analysed.

Stroke mechanisms in these patients were large artery disease in eight, CE in three, cryptogenic stroke in four, and not reported in five patients. Acute complications were not mentioned except for one patient who had delayed haemorrhagic transformation requiring decompression surgery. Among the available data on outcomes, eight patients were discharged either to home $(n=1)$ or rehabilitation facility $(n=4)$ or was not mentioned $(n=3)$; three patients died; five patients were still in the hospital as per the published reports and in four patients details of outcome were not available. Long-term outcomes were not available for these patients.

Anticoagulation was given to 54 (56.3\%) patients, was not indicated in $10(10.4 \%)$ and it was not mentioned whether rest of the patients $32(33.3 \%)$ received any form of anticoagulation. Thirty-three (34.4\%) patients received antiplatelet therapy, 13 (13.6\%) had no indication for the same and 50 (52\%) did not have information with regards to the receipt of antiplatelets. The anticoagulation was therapeutic in some, prophylactic in others and for unclear reasons in rest of them.

Clinical outcome was available for 90 patients (78.2\%). Among them, 17 were still hospitalized at the time of article publication. Among the remaining 73 patients for whom definitive outcomes in terms of survival was available, mortality was observed in 35 (out of 73) patients (47.9\%) and definitive cause of death was not available in all patients. Of note, majority (33 
[94.3\% of 35]) of them were critically ill. In five patients, severe stroke was the proximate cause of death. In four patients, withdrawal of care was requested by the family. In 21 patients, no specific cause was mentioned, but it is likely that a combination of severe COVID-19 as well as comorbidity with stroke caused death, as these patients were critically sick as per the details available. Other causes of death included pneumonia in two patients, severe hemodynamic instability in one, septic shock in one, and systemic thromboembolism in one patient. The clinical and laboratory data was compared between survivors and nonsurvivors (Table 4). Patients who died had more severe illness at the outset. They were more likely to be smokers and to have two or more vascular risk factors, higher levels of D-dimer, CRP, and LDH as compared to survivors. The clinical status of the $17 \mathrm{pa}-$ tients who were still hospitalized by the time the respective articles were published was presented in Supplementary Table 4. Most of these patients were critically ill and at high risk of death. Hence, we conducted a worst case scenario analysis which considered these patients as 'non-survivors' and compared them with 'survivors' (Supplementary Table 5). Factors associated with mortality in this scenario were ICU admission, dyslipidemia, presence of two or more vascular risk factors, high levels of serum ferritin, CRP, D-dimer, and LDH.

\section{Discussion}

The present review summarizes the data from the available literature on stroke in patients with COVID-19. Expanding information on neurological features among patients with COVID-19 indicates cerebrovascular disease as an important comorbidity. ${ }^{8-10}$ Although the data were observational and limited this review would help broaden our understanding regarding the association of COVID-19 and stroke in the current time.

There is still an uncertainty in the relationship between stroke and COVID-19. It is unclear whether it is causative or just coincidental. ${ }^{14-16}$ The median time to develop stroke in the current review was 10 days from the diagnosis of COVID-19 and was much longer in the critically-ill patients. In fact, many of these critically-ill patients had a delayed diagnosis of stroke based on neuroimaging findings due to a lack of clinical suspicion in presence of multisystem dysfunction and/or likely difficulty in assessing the neurological status, particularly in sedated and ventilated patients. This may reflect an impact of infection, inflammation and extreme cytokine activity on systemic and neurological deterioration. ${ }^{17}$ Although cytokine levels were not measured in most of the studies in this review, levels of CRP, ferritin, LDH, and D-dimer were found to be very high and more so among sick patients.
Evidence of abnormal coagulation parameters associated with COVID-19 appeared in early reports from China. The first report of 99 hospitalized patients in Wuhan showed that inflammatory biomarkers of interleukin-6, erythrocyte sedimentation rate, CRP, D-dimer, and other coagulation parameters were increased or deranged. ${ }^{18}$ High levels of D-dimer were observed in the present review which might be due to COVID-19 associated inflammation and the consequent downstream triggering of coagulation cascade. ${ }^{19}$

Higher age and CRP levels were observed among patients symptomatic for COVID-19 at the time of diagnosis of stroke. Reports elucidating differences between COVID-19 positive and COVID-19 negative strokes have also found higher levels of inflammatory biomarkers among the former. ${ }^{10}$ Though this review focused on patients with COVID-19 and stroke, one of the studies included in the present review had compared characteristics of stroke in patients with and without COVID-19. The patients with COVID-19 were younger and often had cryptogenic, severe and fatal strokes. These findings suggest that there may be important differences in the pathophysiology of the stroke with and without COVID-19. ${ }^{10}$

Role of infection in the occurrence of stroke has been previously outlined. ${ }^{20-22}$ Preceding respiratory infections, in particular were found to have a higher association with stroke. The neuroinvasive potential of SARS-CoV-2 and its contribution to stroke is a conundrum. A recent report did not find SARSCoV-2 in the CSF of patients with stroke, ${ }^{23}$ but another contemporary published data from an autopsy series showed viral copies in brain tissue. This autopsy series showed organotropism for multiple organs including lungs, heart, liver, kidneys, brain, and blood, indicating that the virus can directly invade the brain, albeit not preferentially. ${ }^{24}$ In a previous autopsy study, SARS-CoV, which caused a SARS outbreak in 2002 and shares homological sequence with SARS-CoV-2, was identified in the human brain, suggesting that SARS-CoV-2 might also have neurotropism. ${ }^{25}$

Although conventional risk factors were not mentioned in detail among all the studies, higher age, HTN, diabetes, smoking, dyslipidaemia, and AF were commonly observed. Interestingly, comorbidity with cancer was also reported, albeit in few patients. Presence of vascular risk factors could be independently associated with occurrence of stroke among patients with COVID-19. This is supported by the observation that the most common imaging pattern of IS in the present review was infarcts in a single vascular territory with majority of them having LAD. Cryptogenic stroke constituted a significant proportion in this review, but this data could be confounded by the fact that many studies have not outlined stroke aetiology 
probably due to constraints of complete evaluation. Since we did not contact the authors of the published reports individually, this data may not reflect the exact nature of stroke mechanism. Thus, conventional risk factors might play a significant role in the pathogenesis of stroke in patients with COVID-19. In fact, people with underlying vascular risk factors were also likely to have worse outcomes with COVID-19, suggesting a complex relationship between COVID-19, vascular comorbidity, and stroke occurrence. ${ }^{26}$

The pattern of the stroke as well as imaging findings in some patients with multifocal infarcts, haemorrhage and venous thrombosis hints at a disseminated thrombosis ${ }^{27}$ or inflammatory vasculitis, supported by high D-dimer levels, pulmonary thromboembolism ${ }^{26}$ as well as evidence of endothelial inflammation and target organ injury. ${ }^{28-30}$ Presence of APLA and LA in some patients also points towards a prothrombotic cascade. This is also supported by the observation that the second most common pattern of cerebral ischemia on imaging in our review was bi-hemispheric infarcts in multiple vascular territories suggesting a diffuse coagulopathy and these patients had high frequency (7 out of 11 [63.6\%]) of either positive APLA or LA although titres of these antibodies was not available. APLA can induce thrombosis through interference with endogenous anticoagulant mechanisms, activation of platelets, activation of the complement cascade, interaction with endothelial cells and inducing expression of adhesion molecules and tissue factor. ${ }^{31}$ COVID-19 might stimulate the production of APLA as a mechanism of IS, although post infectious APLA is transient and not usually associated with thrombosis. ${ }^{32}$ Pathogenic role of these antibodies among patients with COVID-19 is still uncertain.

Treatment details were available in a limited number of patients for us to make any inference on the benefit or harm of acute stroke therapy. Some patients who seemed to have a usual stroke phenotype were treated with revascularization therapy. In other patients, where stroke was detected incidentally, the patterns of ischemia and unclear onset time might have precluded this treatment. Many patients who were receiving anticoagulation had cryptogenic strokes, suggesting that the underlying mechanisms might have been uncertain and perceived either as embolic or prothrombotic. Considering the fact that SARS-CoV-2 binds to the angiotensin converting enzyme 2 (ACE2) receptor protein and downregulates it, a concern regarding the use of ACE inhibitors in patients with COVID-19 was raised, but was negated due to lack of a sound scientific evidence. ${ }^{33-35}$ We do not have details of patient's medications or biochemical measurements of angiotensin or ACE levels for making a definitive statement in this regard.

High mortality was observed in the current review. Smoking, having two or more vascular risk factors, ICU stay, high D-dimer, CRP, and LDH levels increased the odds of death significantly. Predictors of mortality observed in the previous studies were pneumonia, multiorgan failure ${ }_{1}^{36}$ critically ill state, high CRP, D-dimer, ${ }^{5,19}$ presence of vascular risk factors, and other co-morbidities. $^{8}$

The study has limitations. Individual patient data was missing for many variables and we did not contact authors to gather this information. A high chance of bias exists in view of observational nature of the studies included. The available data pertaining to the differences between COVID-19 positive and negative strokes was very limited at the time of this review. Also, patients with minor strokes may not have been well represented as this study included only COVID positive stroke patients and observations in general suggest that mild strokes presenting to the emergency seemed to have declined during this pandemic. ${ }^{10}$ Caution is advised in the interpretation of laboratory data as information on the temporal profile of tests in relation to the disease onset is not available. We could not assess precise outcomes of stroke survivors due to lack of information about functional disability in majority of the patients and absence of follow-up data.

\section{Conclusions}

The present systematic review suggests that stroke in COVID-19 is probably multifactorial. This is supported by presence of vascular risk factors, a high inflammatory marker response, D-dimer levels and presence of APLAs in these subjects. Outcomes of patients with COVID-19 and associated stroke may be poor, especially among patients with severe COVID-19 and elevated levels of inflammatory markers. Prospectively collected comparative data on stroke phenotypes, treatment details and outcomes among patients with and without COVID-19 is much needed to improve our understanding regarding this emerging association.

\section{Supplementary materials}

Supplementary materials related to this article can be found online at https://doi.org/10.5853/jos.2020.02264.

\section{Disclosure}

The authors have no financial conflicts of interest. 


\section{References}

1. Huang C, Wang Y, Li X, Ren L, Zhao J, Hu Y, et al. Clinical features of patients infected with 2019 novel coronavirus in Wuhan, China. Lancet 2020;395:497-506.

2. WHO coronavirus disease (COVID-19) dashboard. WHO. https://covid19.who.int. 2020. Accessed August 21, 2020.

3. Wang D, Hu B, Hu C, Zhu F, Liu X, Zhang J, et al. Clinical characteristics of 138 hospitalized patients with 2019 novel coronavirus-infected pneumonia in Wuhan, China. JAMA 2020; 323:1061-1069.

4. Zhou F, Yu T, Du R, Fan G, Liu Y, Liu Z, et al. Clinical course and risk factors for mortality of adult inpatients with COVID-19 in Wuhan, China: a retrospective cohort study. Lancet 2020;395:1054-1062.

5. Mao L, Jin H, Wang M, Hu Y, Chen $S$, He $Q$, et al. Neurologic manifestations of hospitalized patients with coronavirus disease 2019 in Wuhan, China. JAMA Neurol 2020;77:1-9.

6. Leonardi M, Padovani A, McArthur JC. Neurological manifestations associated with COVID-19: a review and a call for action. J Neurol 2020;267:1573-1576.

7. Montalvan V, Lee J, Bueso T, De Toledo J, Rivas K. Neurological manifestations of COVID-19 and other coronavirus infections: a systematic review. Clin Neurol Neurosurg 2020;194:105921.

8. Li Y, Li M, Wang M, Zhou Y, Chang J, Xian Y, et al. Acute cerebrovascular disease following COVID-19: a single center, retrospective, observational study. Stroke Vasc Neurol 2020 Jul 2 [Epub]. https://doi.org/10.1136/svn-2020-000431.

9. Oxley TJ, Mocco J, Majidi S, Kellner CP, Shoirah H, Singh IP, et al. Large-vessel stroke as a presenting feature of Covid-19 in the young. N Engl J Med 2020;382:e60.

10. Yaghi S, Ishida K, Torres J, Mac Grory B, Raz E, Humbert $K_{1}$ et al. SARS-CoV-2 and stroke in a New York healthcare system. Stroke 2020;51:2002-2011.

11. Moher D, Liberati A, Tetzlaff J, Altman DG; PRISMA Group. Preferred reporting items for systematic reviews and metaanalyses: the PRISMA statement. Ann Intern Med 2009;151: 264-269.

12. Adams HP Jr, Bendixen BH, Kappelle $\sqcup$, Biller J, Love BB, Gordon $\mathrm{DL}$, et al. Classification of subtype of acute ischemic stroke. Definitions for use in a multicenter clinical trial. TOAST. Trial of Org 10172 in Acute Stroke Treatment. Stroke 1993;24: 35-41.

13. Oxford Centre for Evidence-based Medicine: Levels of Evidence (March 2009). CEBM. https://www.cebm.net/2009/06/ oxford-centre-evidence-based-medicine-levels-evidencemarch-2009. Accessed August 21,2020.

14. Barrios-López JM, Rego-García I, Muñoz Martínez C, Rome-
ro-Fábrega JC, Rivero Rodríguez $M$, Ruiz Giménez JA, et al. Ischaemic stroke and SARS-CoV-2 infection: a causal or incidental association? Neurologia 2020;35:295-302.

15. Lindsberg PJ, Grau AJ. Inflammation and infections as risk factors for ischemic stroke. Stroke 2003;34:2518-2532.

16. Desforges M, Le Coupanec A, Dubeau P, Bourgouin A, Lajoie $L$, Dubé $M$, et al. Human coronaviruses and other respiratory viruses: underestimated opportunistic pathogens of the central nervous system? Viruses 2019;12:14.

17. Sarzi-Puttini P, Giorgi V, Sirotti S, Marotto D, Ardizzone S, Rizzardini G, et al. COVID-19, cytokines and immunosuppression: what can we learn from severe acute respiratory syndrome? Clin Exp Rheumatol 2020;38:337-342.

18. Chen N, Zhou M, Dong X, Qu J, Gong F, Han Y, et al. Epidemiological and clinical characteristics of 99 cases of 2019 novel coronavirus pneumonia in Wuhan, China: a descriptive study. Lancet 2020;395:507-513.

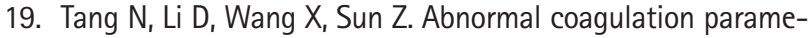
ters are associated with poor prognosis in patients with novel coronavirus pneumonia. J Thromb Haemost 2020;18:844847.

20. Smeeth $L$, Thomas $S L$, Hall AJ, Hubbard R, Farrington $P$, Vallance $P$. Risk of myocardial infarction and stroke after acute infection or vaccination. N Engl J Med 2004;351:2611-2618.

21. Boehme AK, Luna J, Kulick ER, Kamel H, Elkind MSV. Influenza-like illness as a trigger for ischemic stroke. Ann Clin Transl Neurol 2018;5:456-463.

22. Lee KR, Bae JH, Hwang IC, Kim KK, Suh HS, Ko KD. Effect of influenza vaccination on risk of stroke: a systematic review and meta-analysis. Neuroepidemiology 2017;48:103-110.

23. Al Saiegh F, Ghosh R, Leibold A, Avery MB, Schmidt RF, Theofanis $T$, et al. Status of SARS-CoV-2 in cerebrospinal fluid of patients with COVID-19 and stroke. J Neurol Neurosurg Psychiatry 2020;91:846-848.

24. Puelles VG, Lütgehetmann $M$, Lindenmeyer MT, Sperhake JP,

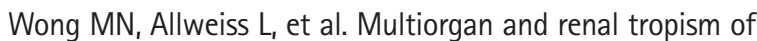
SARS-CoV-2. N Engl J Med 2020;383:590-592.

25. Xu J, Zhong S, Liu J, Li L, Li Y, Wu X, et al. Detection of severe acute respiratory syndrome coronavirus in the brain: potential role of the chemokine mig in pathogenesis. Clin Infect Dis 2005:41:1089-1096.

26. Aggarwal G, Lippi G, Michael Henry B. Cerebrovascular disease is associated with an increased disease severity in patients with coronavirus disease 2019 (COVID-19): a pooled analysis of published literature. Int J Stroke 2020;15:385-389.

27. Lodigiani C, lapichino G, Carenzo L, Cecconi M, Ferrazzi P, Sebastian $T$, et al. Venous and arterial thromboembolic complications in COVID-19 patients admitted to an academic 
hospital in Milan, Italy. Thromb Res 2020;191:9-14.

28. Varga $Z$, Flammer $A$, Steiger $P$, Haberecker $M$, Andermatt $R$, Zinkernagel AS, et al. Endothelial cell infection and endotheliitis in COVID-19. Lancet 2020;395:1417-1418.

29. Thornton $P$, McColl BW, Greenhalgh A, Denes A, Allan SM, Rothwell NJ. Platelet interleukin-1alpha drives cerebrovascular inflammation. Blood 2010;115:3632-3639.

30. Fox SE, Akmatbekov A, Harbert JL, Li G, Quincy Brown J, Vander Heide RS. Pulmonary and cardiac pathology in African American patients with COVID-19: an autopsy series from New Orleans. Lancet Respir Med 2020;8:681-686.

31. Panichpisal K, Rozner E, Levine SR. The management of stroke in antiphospholipid syndrome. Curr Rheumatol Rep 2012;14:99-106.

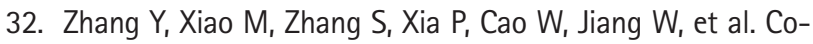

agulopathy and antiphospholipid antibodies in patients with COVID-19. N Engl J Med 2020;382:e38.

33. Hess DC, Eldahshan W, Rutkowski E. COVID-19-related stroke. Trans/ Stroke Res 2020;11:322-325.

34. de Abajo FJ, Rodríguez-Martín S, Lerma V, Mejía-Abril G, Aguilar M, Garcia-Luque $A$, et al. Use of renin-angiotensin-aldosterone system inhibitors and risk of COVID-19 requiring admission to hospital: a case-population study. Lancet 2020;395: 1705-1714.

35. Williams B, Zhang Y. Hypertension, renin-angiotensin-aldosterone system inhibition, and COVID-19. Lancet 2020;395:16711673.

36. Sharifi-Razavi A, Karimi N, Rouhani N. COVID-19 and intracerebral haemorrhage: causative or coincidental? New Microbes New Infect 2020;35:100669. 
Supplementary Table 1. Study assessment according to Oxford Centre for Evidence-based Medicine's Levels of Evidence and Grades of Recommendation ${ }^{1, *}$

\begin{tabular}{|c|c|c|c|c|c|c|}
\hline Study & Study type & $\begin{array}{l}\text { Therapy/ } \\
\text { prevention/ } \\
\text { etiology/harm }\end{array}$ & Diagnosis & Prognosis & $\begin{array}{c}\text { Differential } \\
\text { diagnosis/symptom } \\
\text { prevalence }\end{array}$ & $\begin{array}{c}\text { Economic/decision } \\
\text { analysis }\end{array}$ \\
\hline Beyrouti et al. $^{2}$ & Case Series & IV & NA & IC & IV & NA \\
\hline Viguier et al. ${ }^{3}$ & Case report & IV & NA & IC & IV & NA \\
\hline Avula et al. ${ }^{4}$ & Retrospective observational study & IIB & NA & IIB & IIB & NA \\
\hline Zhou et al. ${ }^{5}$ & Case report & IV & NA & IC & IV & NA \\
\hline Sharifi-Razavi et al. ${ }^{6}$ & Case report & IV & NA & IC & IV & NA \\
\hline Zhang et al. ${ }^{7}$ & Case series & IV & NA & IC & IV & NA \\
\hline Morassi et al. ${ }^{8}$ & Case series & IV & NA & IC & IV & NA \\
\hline Helms et al. ${ }^{9}$ & Prospective cohort study & IIB & NA & IIB & IIB & NA \\
\hline González-Pinto et al. ${ }^{10}$ & Case report & IV & NA & IC & IV & NA \\
\hline Oxley et al. ${ }^{11}$ & Case series & IV & NA & IC & IV & NA \\
\hline Klok et al. ${ }^{12}$ & Retrospective observational study & $\| \mathrm{B}$ & NA & IIB & IV & NA \\
\hline Al Saiegh et al. ${ }^{13}$ & Case series & IV & NA & IC & IV & NA \\
\hline Zhai et al. ${ }^{14}$ & Case report & IV & NA & IC & IV & NA \\
\hline Yaghi et al. ${ }^{15}$ & Retrospective observational study & IIB & NA & IIB & IIB & NA \\
\hline Valderrama et al. ${ }^{16}$ & Case report & IV & NA & IC & IV & NA \\
\hline He et al. ${ }^{17}$ & Case report & IV & NA & IC & IV & NA \\
\hline Li et al. ${ }^{18}$ & Retrospective observational study & $\| \mathrm{B}$ & NA & IIB & $\| \mathrm{B}$ & NA \\
\hline Mao et al. ${ }^{19}$ & Retrospective observational study & IIB & NA & IIB & IIB & NA \\
\hline Helms et al. ${ }^{20}$ & Retrospective observational study & IIB & NA & IIB & IIB & NA \\
\hline Lodigiani et al. ${ }^{21}$ & Retrospective observational study & IIB & NA & IIB & IIB & NA \\
\hline TunÇ et al. ${ }^{22}$ & Case series & IV & NA & IC & IV & NA \\
\hline Muhammad et al. ${ }^{23}$ & Case report & IV & NA & IC & IV & NA \\
\hline Garaci et al..$^{24}$ & Case report & IV & NA & IC & IV & NA \\
\hline Moshayedi et al..$^{25}$ & Case report & IV & NA & IC & IV & NA \\
\hline Zulfiqar et al. ${ }^{26}$ & Case report & IV & NA & IC & IV & NA \\
\hline Chen et al. ${ }^{27}$ & Case report & IV & NA & IC & IV & NA \\
\hline Co et al. ${ }^{28}$ & Case report & IV & NA & IC & IV & NA \\
\hline Deliwala et al. ${ }^{29}$ & Case report & IV & NA & IC & IV & NA \\
\hline Goldberg et al. ${ }^{30}$ & Case report & IV & NA & IC & IV & NA \\
\hline Dahl-Cruz et al. ${ }^{31}$ & Case report & IV & NA & IC & IV & NA \\
\hline
\end{tabular}

NA, not available.

*Rated from IA to V based on Oxford Centre for Evidence-based Medicine's Levels of Evidence and Grades of Recommendation. 
Supplementary Table 2. Results of search for various keyword sets

\begin{tabular}{|c|c|c|c|c|}
\hline \multirow{2}{*}{ Keywords } & \multicolumn{2}{|c|}{ PubMed searches } & \multicolumn{2}{|c|}{ Scopus, Embase, and Web of Science searches } \\
\hline & Relevant & Not relevant & Relevant & Not relevant \\
\hline Thrombolysis and COVID-19 & 5 & 45 & 1 & 24 (13 duplicates) \\
\hline Thrombectomy and COVID-19 & 5 (all duplicates) & 29 (18 duplicates) & 3 (all duplicates) & 11 (9 duplicates) \\
\hline Thrombolysis and SARS-CoV-2 & 5 (all duplicates) & 26 (all duplicates) & 0 & 7 (all duplicates) \\
\hline Thrombectomy and SARS-CoV-2 & 6 (5 duplicates) & 14 (7 duplicates) & 0 & 1 (duplicate) \\
\hline Stroke imaging and COVID-19 & 15 (5 duplicates) & 95 (11 duplicates) & 3 (all duplicates) & 5 (11 duplicates) \\
\hline SARS-CoV-2 and stroke & 23 (19 duplicates) & 150 (49 duplicates) & 6 (4 duplicates) & 33 (28 duplicates) \\
\hline SARS-CoV-2 and neurology & 27 (20 duplicates) & 95 (23 duplicates) & 3 (all duplicates) & 46 (43 duplicates) \\
\hline SARS-CoV-2 and ischemic stroke & 28 (26 duplicates) & 50 (44 duplicates) & 1 (all duplicate) & 7 (6 duplicates) \\
\hline SARS-CoV-2 and ICH & 17 (16 duplicates) & 45 (19 duplicates) & 0 & 2 (1 duplicate) \\
\hline SARS-CoV-2 and cerebrovascular disease & 24 (all duplicates) & 143 (56 duplicates) & 1 (all duplicate) & 18 (17 duplicates) \\
\hline SARS COV2 and intracerebral hemorrhage & 5 (all duplicates) & 29 (all duplicates) & 0 & 0 \\
\hline COVID-19 and stroke & 34 (27 duplicates) & 341 (306 duplicates) & 30 (28 duplicates) & 178 (158 duplicates) \\
\hline COVID-19 and neurology & 34 (30 duplicates) & 185 (174 duplicates) & 12 (all duplicates) & 151 (87 duplicates) \\
\hline COVID-19 and ischemic stroke & 31 (all duplicates) & 105 (97 duplicates) & 8 (all duplicates) & 51 (33 duplicates) \\
\hline COVID-19 and ICH & 21 (all duplicates) & 119 (79 duplicates) & 4 (all duplicates) & 9 (4 duplicates) \\
\hline COVID-19 and cerebrovascular disease & 21 (all duplicates) & 211 (199 duplicates) & 19 (all duplicates) & 103 (68 duplicates) \\
\hline COVID-19 and intracerebral hemorrhage & 8 (all duplicates) & 71 (all duplicates) & 2 (all duplicates) & 2 (1 duplicate) \\
\hline
\end{tabular}

COVID-19, coronavirus disease 2019; SARS-CoV-2, severe acute respiratory syndrome coronavirus 2; ICH, intracerebral haemorrhage. 


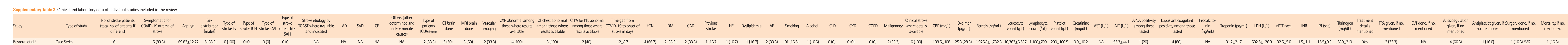
F

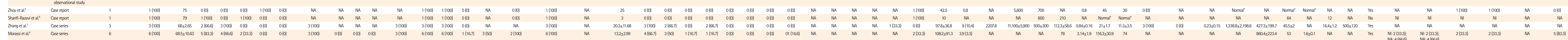
E Emin

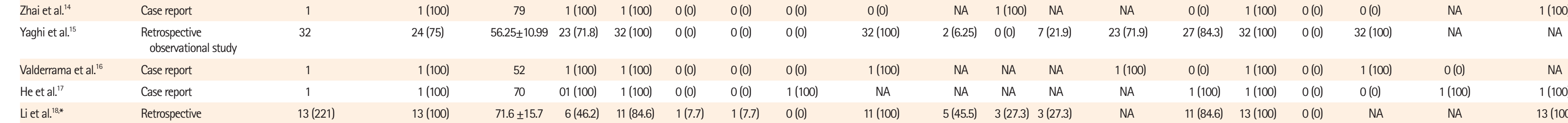

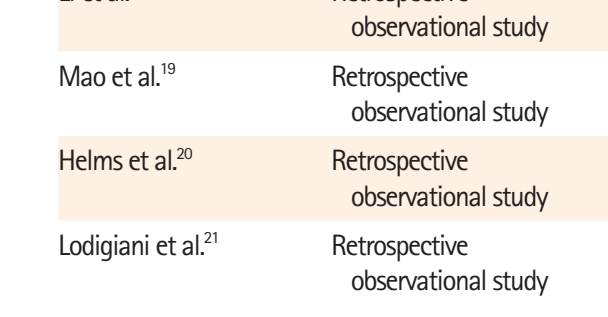


Supplementary Table 4. Clinical status of patients who were still hospitalised at the time of publication of corresponding articles

\begin{tabular}{|c|c|c|c|}
\hline Name of the study* & $\begin{array}{l}\text { No. of still hospitalized } \\
\text { patients at the time of } \\
\text { publication (\%) }\end{array}$ & $\begin{array}{l}\text { Basic demographic features and type of } \\
\text { stroke of individual patients }\end{array}$ & $\begin{array}{c}\text { Clinical status of individual patients as available in the } \\
\text { respective publications }\end{array}$ \\
\hline \multirow[t]{2}{*}{ Oxley et al..$^{11}(n=5)$} & \multirow[t]{2}{*}{$2(40)$} & $\begin{array}{l}\text { 39-year-old male with posterior circulation IS } \\
\text { caused by LAD and admission NIHSS of } 16\end{array}$ & $\begin{array}{l}\text { In ICU with multiorgan failure and was on mechanical } \\
\text { ventilation and sedation }\end{array}$ \\
\hline & & $\begin{array}{l}\text { 44-year-old male with anterior circulation IS } \\
\text { caused by LAD with admission NIHSS of } 23\end{array}$ & $\begin{array}{l}\text { In a stroke unit with NIHSS of } 19 \text { on day } 12 \text { of } \\
\text { admission }\end{array}$ \\
\hline Al Saiegh et al. ${ }^{13}(n=2)$ & $1(50)$ & $\begin{array}{l}\text { 62-year-old female with anterior circulation IS } \\
\text { caused by LAD }\end{array}$ & $\begin{array}{l}\text { She was initially discharged and later readmitted with } \\
\text { altered sensorium. Imaging showed haemorrhagic } \\
\text { transformation with obstructive hydrocephalus. } \\
\text { Tracheostomized with poor Glasgow coma scale and } \\
\text { extra ventricular drain in place. }\end{array}$ \\
\hline \multirow[t]{3}{*}{ Lodigiani et al. ${ }^{21}(n=9)$} & \multirow[t]{3}{*}{3 (33.33) } & 68-year-old male with IS & $\begin{array}{l}\text { In general ward. Further details about clinical status } \\
\text { not mentioned. }\end{array}$ \\
\hline & & 69-year-old male with IS caused by LAD & $\begin{array}{l}\text { In ICU. Further details about clinical status not } \\
\text { mentioned. }\end{array}$ \\
\hline & & 57-year-old male with IS & $\begin{array}{l}\text { In ICU and also had necrotising meningoencephalitis. } \\
\text { Further details about clinical status not mentioned. }\end{array}$ \\
\hline \multirow[t]{10}{*}{ Yaghi et al. ${ }^{15}(n=32)$} & \multirow[t]{10}{*}{$10(31.3)$} & 60-year-old with cryptogenic IS & $\begin{array}{l}\text { Critically ill (no further characterisation of outcome } \\
\text { available) }\end{array}$ \\
\hline & & 70-year-old with cardioembolic IS & $\begin{array}{l}\text { Critically ill (no further characterisation of outcome } \\
\text { available) }\end{array}$ \\
\hline & & 40-year-old with cryptogenic IS & $\begin{array}{l}\text { Critically ill (no further characterisation of outcome } \\
\text { available) }\end{array}$ \\
\hline & & 50-year-old with cryptogenic IS & $\begin{array}{l}\text { Critically ill (no further characterisation of outcome } \\
\text { available) }\end{array}$ \\
\hline & & 60-year-old with cryptogenic IS & $\begin{array}{l}\text { Critically ill (no further characterisation of outcome } \\
\text { available) }\end{array}$ \\
\hline & & $\begin{array}{l}60 \text {-year-old with watershed IS due to } \\
\text { hypotension }\end{array}$ & $\begin{array}{l}\text { Critically ill (no further characterisation of outcome } \\
\text { available) }\end{array}$ \\
\hline & & $\begin{array}{l}70 \text {-year-old with watershed IS due to } \\
\text { hypotension }\end{array}$ & $\begin{array}{l}\text { Critically ill (no further characterisation of outcome } \\
\text { available) }\end{array}$ \\
\hline & & 40-year-old with cryptogenic IS & $\begin{array}{l}\text { Critically ill (no further characterisation of outcome } \\
\text { available) }\end{array}$ \\
\hline & & 50-year-old with cryptogenic IS & $\begin{array}{l}\text { Critically ill (no further characterisation of outcome } \\
\text { available) }\end{array}$ \\
\hline & & 60-year-old with cryptogenic IS & $\begin{array}{l}\text { Critically ill (no further characterisation of outcome } \\
\text { available) }\end{array}$ \\
\hline Co et al. ${ }^{28}(n=1)$ & $1(100)$ & 62-year-old female with IS caused by LAD & $\begin{array}{l}\text { In ICU being managed for COVID-19 infection with } \\
\text { NIHSS of } 4\end{array}$ \\
\hline
\end{tabular}

IS, ischaemic stroke; LAD, large artery disease; NIHSS, National Institutes of Health Stroke Scale; ICU, intensive care unit; COVID-19, coronavirus disease 2019. *Number of patients with stroke in each study. 
Supplementary Table 5. Comparison of survivors and non-survivors assuming worst case scenario*

\begin{tabular}{|c|c|c|c|c|}
\hline Variable & Survivors ( $n=38$ ) & Non-survivors $(n=52)$ & $P^{+}$ & $\mathrm{OR}(95 \% \mathrm{Cl})^{*}$ \\
\hline Age $(n=90)(y r)$ & $60.5 \pm 16.6$ & $63.2 \pm 13.9$ & 0.49 & $1(0.98-1)$ \\
\hline $\operatorname{Sex}(n=57)$ & & & 0.2 & $0.5(0.2-1.5)$ \\
\hline Female & $15(26.3)$ & $9(15.8)$ & & \\
\hline Male & $15(26.3)$ & $18(31.6)$ & & \\
\hline Symptomatic for COVID-19 at the time of stroke $(n=77)$ & $27(35.1)$ & $37(48.1)$ & 0.79 & $1.2(0.35-3.9)$ \\
\hline Type of stroke $(n=90)$ & & & 0.1 & $1.8(0.5-6.3)^{\S}$ \\
\hline Ischaemic stroke & $32(35.6)$ & $47(52.2)$ & & \\
\hline Intracerebral haemorrhage & $0(0)$ & $4(4.4)$ & & \\
\hline Intracerebral haemorrhage with subarachnoid haemorrhage & $2(2.2)$ & $1(1.1)$ & & \\
\hline Cerebral venous thrombosis & $2(2.2)$ & $0(0)$ & & \\
\hline Subarachnoid haemorrhage & $1(1.1)$ & $0(0)$ & & \\
\hline Transient ischaemic attack & $1(1.1)$ & $0(0)$ & & \\
\hline NIHSS $(n=16)$ & $11.5(4.5-16.8)$ & $10(2-26.3)$ & 0.59 & $1(0.9-1.2)$ \\
\hline TOAST $(n=67)$ & & & 0.057 & \\
\hline Large artery disease & $12(17.9)$ & $12(17.9)$ & & $0.67(0.1-3)$ \\
\hline Small vessel disease & $5(7.5)$ & $1(1.5)$ & & $0.1(0.01-1.6)$ \\
\hline Cardioembolic & $4(5.9)$ & $6(8.9)$ & & $1.5(0.4-5.3)$ \\
\hline Other & $0(0)$ & $4(5.9)$ & & NA \\
\hline Cryptogenic & $6(8.9)$ & $17(25.4)$ & & $1.9(0.4-9.1)$ \\
\hline Critical illness $(n=90)$ & & & $<0.0001^{\|}$ & \\
\hline No & $21(23.3)$ & $3(3.3)$ & & $0.1(0.04-0.5)$ \\
\hline Yes & 17 (18.9) & $49(54.5)$ & & $20.2(5.3-76.3)$ \\
\hline Chest X-ray $(n=9)$ & & & 0.86 & NA \\
\hline Normal & $1(11.1)$ & $1(11.1)$ & & \\
\hline Abnormal & $3(33.3)$ & $4(44.4)$ & & \\
\hline Abnormal CT chest $(n=38)$ & $20(52.6)$ & $18(47.4)$ & NA & NA \\
\hline Abnormal CT pulmonary angiography $(n=3)$ & $1(33.3)$ & $1(33.3)$ & 0.39 & NA \\
\hline \multicolumn{5}{|l|}{ Risk factors } \\
\hline Hypertension ( $\mathrm{n}=89$ ) & $14(15.7)$ & $21(23.6)$ & 0.68 & $1.2(0.5-2.8)$ \\
\hline Diabetes $(n=89)$ & $7(7.9)$ & $13(14.6)$ & 0.43 & $1.5(0.5-4.3)$ \\
\hline Old stroke $(n=89)$ & $1(1.1)$ & $3(3.4)$ & 0.5 & $2.3(0.2-27)$ \\
\hline Smoking $(n=53)$ & $2(3.8)$ & $6(11.3)$ & 0.087 & $4.1(0.7-23)$ \\
\hline Atrial fibrillation $(n=88)$ & $4(4.5)$ & $6(6.8)$ & 0.83 & $1.2(0.3-4.4)$ \\
\hline Heart failure $(n=88)$ & $0(0)$ & $4(4.5)$ & 0.07 & NA \\
\hline Pacemaker $(\mathrm{n}=88)$ & $0(0)$ & $1(1.1)$ & 0.38 & NA \\
\hline Dyslipidemia $(n=82)$ & $6(7.3)$ & $17(20.7)$ & $0.04^{\prime \prime}$ & $2.9(1-8.5)$ \\
\hline Coronary artery disease $(n=88)$ & $1(1.1)$ & $6(6.8)$ & 0.1 & $5(0.6-43.8)$ \\
\hline Alcoholism $(n=48)$ & $1(2.1)$ & $1(2.1)$ & 0.86 & $1.3(0.1-22)$ \\
\hline No. of risk factors $(n=89)$ & & & $0.002^{\prime \prime}$ & \\
\hline 0 & $16(17.9)$ & $6(6.7)$ & & $0.4(0.2-0.9)$ \\
\hline 1 & $7(7.9)$ & $8(8.9)$ & & $3(0.8-12.1)$ \\
\hline$\geq 2$ & 15 (16.9) & $37(41.6)$ & & $6.6(2.2-20)$ \\
\hline \multicolumn{5}{|l|}{ Comorbidities } \\
\hline Chronic kidney disease $(n=10)$ & $1(10)$ & $0(0)$ & 0.49 & NA \\
\hline Cancer $(n=12)$ & $1(8)$ & $1(8)$ & 0.79 & $1.5(0.1-32)$ \\
\hline
\end{tabular}


Supplementary Table 5. Continued

\begin{tabular}{|c|c|c|c|c|}
\hline Variable & Survivors $(n=38)$ & Non-survivors $(n=52)$ & $P^{+}$ & $\mathrm{OR}(95 \% \mathrm{CI})^{*}$ \\
\hline C-reactive protein $(n=54)(\mathrm{mg} / \mathrm{L})$ & $81 \pm 95$ & $145 \pm 102$ & $0.009^{\prime \prime}$ & $2.7(0.8-8.3)^{\uparrow}$ \\
\hline D-dimer $(n=60)(\mu \mathrm{g} / \mathrm{L})$ & $3,180 \pm 3,658$ & $7,514 \pm 10,308$ & $0.006^{\prime \prime}$ & $2.7(0.9-8.1)^{* *}$ \\
\hline Ferritin $(n=12)(\mu \mathrm{g} / \mathrm{L})$ & $241 \pm 228$ & $2,253 \pm 1,611$ & $0.0066^{\|}$ & $N A^{+t}$ \\
\hline Leucocyte count $(n=20)\left(\times 10^{9} / \mathrm{L}\right)$ & $8.3 \pm 3$ & $12.6 \pm 7$ & 0.2 & $4(0.6-29.1)$ \\
\hline Lymphocyte $(n=16)\left(\times 10^{9} / L\right)$ & $1 \pm 0.5$ & $0.99 \pm 0.7$ & 0.71 & $0.6(0.1-4.4)$ \\
\hline Platelet $(n=17)\left(\times 10^{9} / L\right)$ & $245 \pm 93$ & $226 \pm 120$ & 0.3 & NA \\
\hline Creatinine $(n=11)(\mu \mathrm{mol} / \mathrm{L})$ & $113 \pm 45$ & $162 \pm 133$ & 1 & $1.2(0.1-20)$ \\
\hline Aspartate transaminase $(n=11)(\mathrm{U} / \mathrm{L})$ & $50 \pm 37$ & $69 \pm 48$ & 0.71 & $1.3(0.1-16)$ \\
\hline Alanine transaminase $(n=9)(U / L)$ & $31 \pm 18$ & $39 \pm 21$ & 0.6 & NA \\
\hline Procalcitonin $(n=5)(\mu \mathrm{g} / \mathrm{L})$ & $0.08^{\S \S}$ & $4.68 \pm 6.4$ & 0.16 & NA \\
\hline Troponin $(\mathrm{n}=16)(\mathrm{pg} / \mathrm{mL})$ & $310 \pm 348$ & $2,245 \pm 4,904$ & 0.16 & $1.2(0.7-20)$ \\
\hline Lactate dehydrogenase $(n=12)(U / L)$ & $302 \pm 99$ & $761 \pm 235$ & $0.01^{\prime \prime}$ & $N A^{\neq \neq}$ \\
\hline aPTT $(n=10)(\mathrm{sec})$ & $26 \pm 14$ & $37 \pm 10$ & 0.25 & $2.67(0.2-45)$ \\
\hline International normalized ratio $(n=6)$ & $1.2 \pm 0$ & $1.95 \pm 1.1$ & 0.35 & NA \\
\hline Prothrombin time $(n=6)$ & $13.9 \pm 1.1$ & $13.7 \pm 0.8$ & 0.83 & NA \\
\hline Fibrinogen $(n=9)(g / L)$ & $4.9 \pm 1.9$ & $6.3 \pm 1.6$ & 0.44 & NA \\
\hline APLA positivity $(n=4)$ & $0(0)$ & $0(0)$ & NA & NA \\
\hline Lupus anticoagulant $(n=2)$ & $0(0)$ & $1(50)$ & NA & NA \\
\hline
\end{tabular}

Values are presented as mean \pm standard deviation, number (\%), or median (interquartile range).

OR, odds ratio; Cl, confidence interval; COVID-19, coronavirus disease 2019; NIHSS, National Institutes of Health Stroke Scale; TOAST, Trial of ORG 10172 in Acute Stroke Treatment; NA, not applicable; CT, computed tomography; aPTT, activated partial thromboplastin time; APLA, antiphospholipid antibody.

*Data is not uniformly available for each patient leading to separate ' $n$ ' number for each characteristic; ${ }^{\dagger}$ Chi-square test was used for categorical variables and Mann-Whitney test was used for continuous variables to calculate $P$-value unless otherwise specified; ${ }^{\dagger}$ ORs were calculated by logistic regression. The cut-off values used for calculating ORs were upper or lower limits of normal values (whichever differentiates normal from abnormal values) unless otherwise specified; ${ }^{5} \mathrm{OR}$ was calculated for ischaemic stroke when compared with non-ischaemic stroke; "The difference between the groups was statistically significant; ${ }^{\circ} \mathrm{A}$ C-reactive protein (CRP) cut-off value of $100 \mathrm{mg} / \mathrm{L}$ was used arbitrarily to calculate the OR. The difference between the groups for CRP was significant by Mann-Whitney test even though the $\mathrm{Cl}$ for $\mathrm{OR}$ included $1 ;{ }^{*} \mathrm{D}$-dimer cut-off of $4,000 \mu \mathrm{g} / \mathrm{L}$ was used arbitrarily to calculate $\mathrm{OR}$; ${ }^{++} O$ ne of the cells in the contingency table used to calculate $\mathrm{OR}$ at a cut-off of $300 \mu \mathrm{g} / \mathrm{L}$ of serum ferritin had null value precluding the calculation of the same. Only single observation was available; ${ }^{\neq \dagger}$ One of the cells in the contingency table used to calculate $O R$ at a cut-off of $280 \mathrm{U} / \mathrm{L}$ of lactate dehydrogenase had null value precluding the calculation of the same; ${ }^{\S}$ Only single observation was available. 


\section{Supplementary References}

1. Oxford Centre for Evidence-based Medicine: Levels of Evidence (March 2009). CEBM. https://www.cebm.net/2009/06/ oxford-centre-evidence-based-medicine-levels-evidencemarch-2009. Accessed August 21,2020.

2. Beyrouti R, Adams ME, Benjamin L, Cohen H, Farmer SF, Goh $Y Y$, et al. Characteristics of ischaemic stroke associated with COVID-19. J Neurol Neurosurg Psychiatry 2020;91:889-891.

3. Viguier A, Delamarre L, Duplantier J, Olivot JM, Bonneville F. Acute ischemic stroke complicating common carotid artery thrombosis during a severe COVID-19 infection. J Neuroradiol 2020;47:393-394.

4. Avula A, Nalleballe K, Narula N, Sapozhnikov S, Dandu V, Toom S, et al. COVID-19 presenting as stroke. Brain Behav Immun 2020;87:115-119.

5. Zhou B, She J, Wang Y, Ma X. A case of coronavirus disease 2019 with concomitant acute cerebral infarction and deep vein thrombosis. Front Neurol 2020;11:296.

6. Sharifi-Razavi A, Karimi N, Rouhani N. COVID-19 and intracerebral haemorrhage: causative or coincidental? New Microbes New Infect 2020;35:100669.

7. Zhang $Y$, Xiao M, Zhang S, Xia P, Cao W, Jiang W, et al. Coagulopathy and antiphospholipid antibodies in patients with Covid-19. N Engl J Med 2020;382:e38.

8. Morassi M, Bagatto D, Cobelli M, D'Agostini S, Gigli GL, Bnà $C_{\text {, et }}$ al. Stroke in patients with SARS-CoV-2 infection: case series. J Neurol 2020;267:2185-2192.

9. Helms J, Tacquard C, Severac F, Leonard-Lorant I, Ohana M, Delabranche $X_{1}$ et al. High risk of thrombosis in patients with severe SARS-CoV-2 infection: a multicenter prospective cohort study. Intensive Care Med 2020;46:1089-1098.

10. González-Pinto $T$, Luna-Rodríguez $A$, Moreno-Estébanez $A$, Agirre-Beitia G, Rodríguez-Antigüedad A, Ruiz-Lopez M. Emergency room neurology in times of COVID-19: malignant ischaemic stroke and SARS-CoV-2 infection. Eur J Neurol 2020;27:e35-e36.

11. Oxley TJ, Mocco J, Majidi S, Kellner CP, Shoirah H, Singh IP, et al. Large-vessel stroke as a presenting feature of Covid-19 in the young. N Engl J Med 2020;382:e60.

12. Klok FA, Kruip MJ, van der Meer NJM, Arbous MS, Gommers $\mathrm{DA}$, Kant KM, et al. Incidence of thrombotic complications in critically ill ICU patients with COVID-19. Thromb Res 2020; 191:145-147.

13. Al Saiegh F, Ghosh R, Leibold A, Avery MB, Schmidt RF, Theofanis T, et al. Status of SARS-CoV-2 in cerebrospinal fluid of patients with COVID-19 and stroke. J Neurol Neurosurg Psychiatry 2020;91:846-848.
14. Zhai $P$, Ding $Y$, Li Y. The impact of COVID-19 on ischemic stroke. Diagn Pathol 2020;15:78.

15. Yaghi S, Ishida K, Torres J, Mac Grory B, Raz E, Humbert K, et al. SARS-CoV-2 and stroke in a New York Healthcare System. Stroke 2020;51:2002-2011.

16. Valderrama EV, Humbert K, Lord A, Frontera J, Yaghi S. Severe acute respiratory syndrome coronavirus 2 infection and ischemic stroke. Stroke 2020;51:e124-e127.

17. He J, Cheng G, Xu W, Zhang L, Zeng Z. Diagnosis and treatment of an elderly patient with secondary cerebral infarction caused by COVID-19. Nan Fang Yi Ke Da Xue Xue Bao 2020;40: 351-352.

18. Li Y, Li M, Wang M, Zhou Y, Chang J, Xian Y, et al. Acute cerebrovascular disease following COVID-19: a single center, retrospective, observational study. Stroke Vasc Neurol 2020:svn2020-000431.

19. Mao $L$, Jin $H$, Wang $M, H u Y$, Chen $S$, He $Q$, et al. Neurologic manifestations of hospitalized patients with coronavirus disease 2019 in Wuhan, China. JAMA Neurol 2020;77:1-9.

20. Helms J, Kremer $S$, Merdji $H$, Clere-Jehl R, Schenck M, Kum-

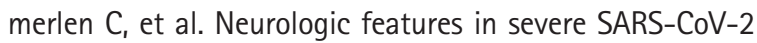
infection. N Engl J Med 2020;382:2268-2270.

21. Lodigiani C, lapichino G, Carenzo L, Cecconi M, Ferrazzi P, Sebastian $T$, et al. Venous and arterial thromboembolic complications in COVID-19 patients admitted to an academic hospital in Milan, Italy. Thromb Res 2020;191:9-14.

22. TunÇ A, ÜnlÜbaŞ Y, Alemdar M, AkyÜz E. Coexistence of COVID-19 and acute ischemic stroke report of four cases. J Clin Neurosci 2020;77:227-229.

23. Muhammad $S$, Petridis $A$, Cornelius JF, Hänggi D. Letter to editor: severe brain haemorrhage and concomitant COVID-19 infection: a neurovascular complication of COVID-19. Brain Behav Immun 2020;87:150-151.

24. Garaci F, Di Giuliano F, Picchi E, Da Ros V, Floris R. Venous cerebral thrombosis in COVID-19 patient. J Neurol Sci 2020;414: 116871.

25. Moshayedi P, Ryan TE, Mejia LL, Nour M, Liebeskind DS. Triage of acute ischemic stroke in confirmed COVID-19: large vessel occlusion associated with coronavirus infection. Front Neurol 2020;11:353.

26. Zulfiqar AA, Lorenzo-Villalba N, Hassler P, Andrès E. Immune thrombocytopenic purpura in a patient with COVID-19. N Engl J Med 2020;382:e43.

27. Chen S, Hu B, Li H, Xia Y, Zhang Y, Mao L, et al. COVID-19 with acute cerebral infarction: one case report. Chin J Neurol 2020;53:309-311.

28. Co CO, Yu JR, Laxamana LC, David-Ona DI. Intravenous thrombolysis for stroke in a COVID-19 positive Filipino pa- 
tient, a case report. J Clin Neurosci 2020;77:234-236.

29. Deliwala S, Abdulhamid S, Abusalih MF, Al-Oasmi MM, Bachuwa G. Encephalopathy as the sentinel sign of a cortical stroke in a patient infected with coronavirus disease-19 (COVID-19). Cureus 2020;12:e8121.

30. Goldberg MF, Goldberg MF, Cerejo R, Tayal AH. Cerebrovascu- lar disease in COVID-19. AJNR Am J Neuroradiol 2020; 41:1170-1172.

31. Dahl-Cruz F, Guevara-Dalrymple N, López-Hernández N. Cerebral venous thrombosis and SARS-CoV-2 infection. Rev Neurol 2020;70:391-392. 